\title{
Assessing the Consequences of Building Failures
}

Victoria Janssens, PhD Student; Dermot W. O’Dwyer, Senior Lecturer; Trinity College, Dublin, Ireland; and Marios K. Chryssanthopoulos, Prof., University of Surrey, Guildford, UK. Contact: janssenv@tcd.ie

DOI: $10.2749 / 101686612 X 13216060213473$

\begin{abstract}
The consequences of structural failures, as a result of a hazard, can take several forms: from material/structural damage and human injuries/fatalities to functional downtime and environmental impact. Within a risk-based robustness framework, consequence modelling is an important step in estimating risk, both in determining the robustness of a building and in assessing the benefit of possible robustness-improving measures. This paper highlights the principles to be adopted in estimating consequences arising from potential building failures. The multi-dimensional and variable aspects of the "cost of failure" are discussed, and the various types of consequences arising from building failure are examined. In this respect, a categorisation of failure consequences is presented, together with associated models for quantifying their magnitude.
\end{abstract}

Keywords: robustness; consequences; buildings; collapse; risk assessment.

\section{Introduction}

Consideration of failure consequences is essential in structural design and assessment, including reliability differentiation ${ }^{1}$ and robustness evaluation. ${ }^{2}$ Table 1 highlights the consequence classes currently adopted in the Eurocode suite; as can be seen, consequences are assumed to be dependent on the building type and function. For the purpose of robustness evaluation, these classes are further elaborated with respect to the size of the building (number of storeys, floor area), function and occupancy.

The distinction between consequence classes, particularly between CC2 and $\mathrm{CC} 3$, is inevitably subjective to a degree. The collapse of a ten-storey building (currently classed as CC2) could result in high loss of human life, depending on the nature and time of the accident. In this regard, a classification based on quantitative thresholds for human and other consequences, rather than indirect indicators, would enable a rationalisation of acceptable risks and of the benefits from specific mitigation measures.

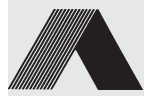

Peer-reviewed by international experts and accepted for publication by SEI Editorial Board
At present, the recommended stiategy $^{2}$ leading to an acceptable lepl bf robustness for $\mathrm{CC} 3$ structurer in volves the undertaking of a systen atic risk assessment, taking inte-account both foreseeable and unforeseable events. The risk assessment can be either qualitative or quantitative but in either case, the acceptable risk ought to be considered tr:ough a consideration of the likelihood of undesirable events and ssociated consequences (typically $n$ the form of a risk matrix). This paper focuses on the explicit modelling and quantification of consequences, as a necessary component in a risk-based robustness evaluation.

\section{Risk-based Robustness}

Within a risk-based framework for the evaluation of robustness ${ }^{3,4}$, the risk $R_{E}$ associated with a particular event $E$ may be assessed through the following product:

$R_{E}=p_{E} C_{E}$

where $p_{E}$ is the probability of the (adverse) event and $C_{E}$ are the consequences arising from the occurrence of the event. As formalised in EN 1991$1-7,{ }^{2}$ a scenario approach with respect to potential hazards, direct damages and follow-up failures can be adopted, thereby expressing the risk related to a particular structure through the following equation:

$$
\begin{aligned}
& R= \\
& \sum_{i=1}^{N_{H}} P\left(H_{i}\right) \sum_{j=1}^{N_{D}} \sum_{k=1}^{N_{S}} P\left(D_{j} \mid H_{i}\right) P\left(S_{k} \mid D_{j}\right) C_{i j}\left(S_{k}\right)
\end{aligned}
$$

where it is assumed that the structure is subjected to $N_{H}$ different hazards (corresponding to single or multiple events), that the hazards may damage the structure in $N_{D}$ different ways (which can be dependent on the considered hazards) and that the performance of the damaged structure can be discretised into $N_{S}$ adverse states $S_{k}$ with corresponding consequences $C\left(S_{k}\right)$. Moreover, $P\left(H_{i}\right)$ is the probability of occurrence (within a reference time interval) of the $i$ th hazard, $P\left(D_{j} \mid H_{i}\right)$ is the conditional probability of the $j$ th damage state given the $i$ th hazard and $P\left(S_{k} \mid D_{j}\right)$ is the conditional probability of the $k$ th adverse overall

\begin{tabular}{|l|l|l|}
\hline Class & Description & Examples \\
\hline CC1 & $\begin{array}{l}\text { Low consequence for loss of } \\
\text { human life, and economic, social } \\
\text { or environmental consequences are } \\
\text { small or negligible }\end{array}$ & $\begin{array}{l}\text { Agricultural buildings where people } \\
\text { do not normally enter (e.g. storage } \\
\text { buildings, greenhouses) }\end{array}$ \\
\hline CC2 & $\begin{array}{l}\text { Medium consequence for loss of } \\
\text { human life, economic, social or } \\
\text { environmental consequences are } \\
\text { considerable }\end{array}$ & $\begin{array}{l}\text { Residential and office buildings, public } \\
\text { buildings where failure consequences } \\
\text { are medium (e.g. office building) }\end{array}$ \\
\hline CC3 & $\begin{array}{l}\text { High consequence for loss of human } \\
\text { life, or economic, social or environ- } \\
\text { mental consequences are very great }\end{array}$ & $\begin{array}{l}\text { Grandstands, public buildings where } \\
\text { the consequences of failure are high } \\
\text { (e.g. concert hall) }\end{array}$ \\
\hline
\end{tabular}

Table 1: Consequence classes adopted in EN 1990 ${ }^{1}$ 
structural performance state given the $j$ th damage state.

Consequences can take various forms (and hence be measured in different units), leading to a vector representation, that is, $\boldsymbol{C}=\left[C_{1}, C_{2}, \ldots C_{m}\right]$. As a result, the above equations would also be expressed in vector form with $\boldsymbol{R}=$ $\left[R_{1}, R_{2}, \ldots R_{\mathrm{m}}\right]$ being a column vector. In the special case, where all consequences are measured through a single quantity for simplicity or convenience (e.g. in monetary units), then a summation of risks can be undertaken, leading to the following expression for the total risk:

$$
R_{\text {total }}=\sum_{m=1}^{N_{E}} R_{m}
$$

Should this be deemed acceptable, a single-objective optimisation problem may be formulated, in which various mitigation and avoidance measures can be assessed through Eq. (3) subject to safety/reliability constraints. Alternatively, in cases where different consequence forms are considered explicitly, multi-objective optimisation and multi-criteria decision analysis may be required, in which the relative weighting between different impacts is dependent on societal preferences determined through stakeholder input.

When performing a risk assessment for robustness purposes using Eqs (1) to (3), the purpose is to determine the magnitude of consequences in relation to a triggering event. In this respect, it is beneficial to sub-divide the consequences into two categories, namely direct and indirect, which may then be used within a risk assessment framework, together with acceptability criteria for different structural forms, types and functions. The separate treatment of direct and indirect consequences can be exploited further by defining a robustness indicator as a simple function of these two components. ${ }^{3}$

Direct consequences are normally associated with initial damage or partial collapse of some constituent elements of the structure. With regard to Eq. (3), direct consequences would be confined to initial damage states, and therefore the associated risk could be evaluated as below:

$$
R_{\text {Direct }}=\sum_{i=1}^{N_{H}} P\left(H_{i}\right) \sum_{j=1}^{N_{D}} P\left(D_{j} \mid H_{i}\right) C_{i}\left(S_{j}\right)
$$

On the other hand, indirect (or follow-up) consequences would extend

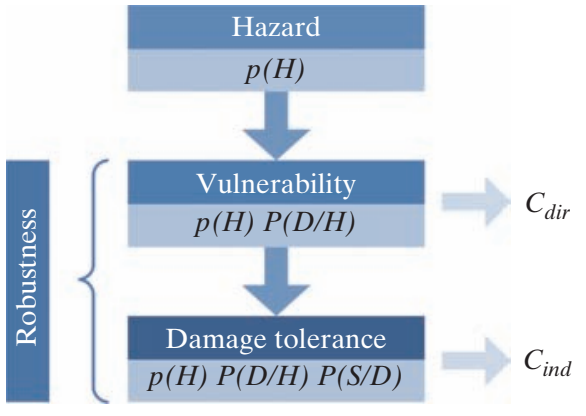

Fig. 1: Distinction between direct and indirect consequences for robustness assessment

beyond initial damages and be associated with any progressive collapse, as well as the ensuing loss of functionality and/or other malfunctions due to adverse combination of constituent failures. The range (and extent) of indirect consequences to be quantified would depend on the definition of the "system" considered in assessing robustness. This system can extend beyond the structure per se and may include the impact on surrounding structures, services and people, as vell as the wider socio-economic tc by ic served by the structure under consideration. For indirect cons quences, the full risk representation as given by Eq. (3), would need to be applied. Figure 1 shows schematical $y$ how these two consequence cenponents relate to the various parts of Eq. (3).

\section{Factor Affecting the Consequences of Failure}

The consequences of building failures vary significantly from structure to structure, and may depend on a wide range of factors; related to the hazard, the structure and its function. Therefore it is important to consider the various influencing factors, and ensure they are well defined, before attempting to quantify the consequences.

Firstly, the nature of the hazard will considerably affect both the scale and type of the consequences considered. In robustness assessment, the hazard can take many different forms, ranging from extreme values of the design actions and accidental actions, to deterioration processes and human errors associated with the design, execution and use of a structure. The type of hazard under consideration will have a considerable influence on the consequences. Additionally, the greater the level and duration of a hazard the more significant the consequences will be. For example, a fire will have an adverse effect on the mechanical properties of the structure, directly affecting its ability to withstand loads, but may also generate fumes and toxic pollutants which could be dispersed in the atmosphere. Moreover, it is also possible for a hazard to create a chain effect: for example, an impact may be followed by an explosion, which may in turn be followed by a fire.

The properties of the structure will influence both the vulnerability and robustness of a building. The consequences will be sensitive to factors such as the materials used, building type, age, size, height, layout (including ease of evacuation), type of construction and quality of construction. The consequences of failure are also dependant on the use or occupancy of a building. This will govern the number of people exposed to the hazard, and therefore the possible number of injuries or fatalities. Additionally, the use or occupancy will influence the building contents and the quality of building services and finishes (e.g. ventilation, plumbing and electrical systems) present.

Buildings in rural areas, or close to a water source, may be more vulnerable to environmental consequences as pollutants are more easily transported in open air/water. In contrast the concentration of people in urban areas will be significantly greater, increasing the number of people exposed to the hazard and therefore the level of human consequences observed. Also, the availability of emergency services and accessibility to treatment for injuries will most likely be best in urban areas. Hence, the proportion of fatalities may be lower in these locations, while an increased number of injuries could be observed (due to the expected increased survival rate). Finally, when studying the cost of repair or reconstruction, remote locations may have higher costs due to increased labour and material costs. In other words, the location of a building will have some bearing on the consequences arising from any given failure event.

Depending on the time of day, different building types may experience different occupancy levels. For instance, places of work and education will experience high levels of occupancy during working hours, whereas at night these buildings may be almost empty. In contrast, residential buildings will reach 
peak occupancy at night, when the occupants are sleeping. Therefore, the potential for mass casualties is dependent on both the time of day the exposure occurs and the occupancy pattern for the structure. Further temporal variations can occur daily, weekly, monthly, seasonally, etc. Additionally, the time frame considered (days/weeks/ years) in the consequence analysis may affect the outcome of such an analysis. For example, the economic and social consequences associated with loss of functionality will be dependent on the period of time over which they are assessed.

Finally, the meteorological conditions, during and after the failure event, may have some impact on the consequences. In particular air conditions (including wind direction, wind speed, terrain, etc.) will influence the level of dispersion of any toxic pollutants, leading to an increase or decrease in the environmental consequences accordingly.

\section{Identification and Categorisation of Consequences}

As discussed in the previous section, the consequences will depend on a wide range of factors related to the system. Therefore, at the onset of any consequence analysis, it is important that a detailed description of the system is developed. This system definition is also of importance when defining the direct and indirect consequences, discussed previously. All possible consequences which may occur should be documented. In general, these may be considered under four main headings: human, economic, environmental and social. At a later stage, and following consultation with the relevant parties, it may be possible to reduce this list by omitting "insignificant" consequences. However, such omissions should be justified and documented.

Table 2 presents an example of the individual consequences which may arise due to a building failure, separated into the proposed categories. This categorisation is consistent with the vector representation of the consequences discussed previously (where each vector component would correspond to the categories above) and allows for the inclusion of a wide range of consequences, possibly with different units of measurement. It should be noted that the different types of consequences within each category may

\begin{tabular}{|l|l|l|}
\hline Category & Direct consequences & Indirect consequences \\
\hline Human & $\begin{array}{l}\text { Injuries } \\
\text { Fatalities }\end{array}$ & $\begin{array}{l}\text { Injuries } \\
\text { Fatalities } \\
\text { Psychological damage }\end{array}$ \\
\hline $\begin{array}{l}\text { Economic } \\
\text { Replacement/repair of contents }\end{array}$ & $\begin{array}{l}\text { Replacement/repair of structure } \\
\text { Replacement/repair of contents }\end{array}$ \\
& $\begin{array}{l}\text { Replacement/repair of nearby } \\
\text { structures } \\
\text { Loss of functionality/production } \\
\text { Temporary relocation } \\
\text { Clean up costs }\end{array}$ \\
& & $\begin{array}{l}\text { Rescue costs } \\
\text { Regional economic effects } \\
\text { Investigation/compensation }\end{array}$ \\
& & $\begin{array}{l}\text { CO }{ }_{2} \text { emissions } \\
\text { Toxic releases } \\
\text { Environmental studies/repair }\end{array}$ \\
\hline Environmental & $\mathrm{CO}_{2}$ emissions & $\begin{array}{l}\text { Loss of reputation } \\
\text { Changes in employment/lifestyle } \\
\text { patterns } \\
\text { Changes in professional practice }\end{array}$ \\
\hline
\end{tabular}

Table 2: Categorisation of consequences

also have different units of neasurement, increasing the complexity of the consequences vector for example is certainly not an exnastive list of the individual consuquences which may occur and should be reviewed on a case-by-ca basis. Finally, a clear distinction belween the different types of orsequences should be made to Censare certain consequences are not omitted or double-counted. For example, if the rescue costs (e.g. fire brigade, ambulance) are considered, one should be careful not to include the costs associated with pre-hospital treatment in the injuries term. Clearly, some of the above categories can be quantified through past experience, statistical modelling and the development of accident scenarios, though the degree of plausibility and desired accuracy is subject to assumptions and idealisations that have not so far been tested to any significant extent.

\section{Quantification of Consequences}

The individual consequences of building failure may be considered to lie within the remit of multiple subject areas (e.g. earthquake engineering loss estimation, economics and epidemiology). This section reviews past experience, from a variety of fields, in quantifying the consequences of failure and presents suggested approaches for estimating mean values for some of these terms. Such single point estimates should be considered as a starting point in estimating consequences, which are typically highly uncertain quantities. However, a probabilistic approach, accounting for both aleatory and epistemic uncertainties, is likely to be most appropriate in the majority of cases.

\section{Fatalities}

Fatality prediction is strongly influenced by the extent and actual mode of failure, which could be captured through the collapsed floor area fraction and its spatial position within the building. These factors should be central to any models which estimate the fatalities arising as a result of building collapse. In the subject area of earthquake loss estimation, such models have been developed and calibrated using field data from various events. Although building collapses as a result of earthquakes may have some differences from those caused by the hazards under consideration in this paper, these models offer a good starting point for predicting the number of fatalities as a result of an extreme event. A model ${ }^{5}$ was presented for predicting the number of fatalities in a particular building, due to building collapse as a result of earthquake, has 
been presented previously. This model defined the number of people killed, $K_{s}$, as:

$$
K_{s}=K_{\max } M_{2} M_{3}\left(M_{4}+M_{5}\right)
$$

where $K_{\max }$ is defined as the maximum number of people in the building and $M_{2}$ to $M_{5}$ are a range of modification factors, with values between zero and one. $M_{2}$ represents the percentage of people in the building at collapse: this may be determined from detailed occupancy studies, or can be taken conservatively as one. $M_{3}$ accounts for the fraction of people trapped by debris. For the failure of buildings, this term should also account for the percentage of people able to evacuate the building before collapse (or, in the case of partial collapse, the portion able to move to a safe part of the building). $M_{4}$ signifies the number of trapped individuals killed instantly by the collapse, which will be largely dependent on the building type. Finally, $M_{5}$ is the post-collapse mortality factor and is related to the building type, as well as the effectiveness of the emergency response.

To determine the usefulness of this model for building failures, the above equation has been applied to a welldocumented example. In 1995, the Alfred P. Murrah federal building, Oklahoma, suffered partial collapse as a result of a malicious bomb attack. ${ }^{6}$ At the time of collapse, there were 361 people in the main nine-storey building, of which 167 died and 156 were injured. ${ }^{7}$ Using floor plans of the building together with images of the collapse, it has been estimated that $40 \%$ of the occupiable floor area in the main building collapsed. For reinforced concrete buildings, it has been proposed $^{8}$ that $40 \%$ of trapped individuals will be killed instantly by the collapse and 70 to $90 \%$ (depending on the effectiveness of the emergency response) of persons injured will consequently die as a result of their injuries. Inserting these values into Eq. (4) predicts that between 159 and 188 fatalities would be expected for a collapse of this magnitude. This is in good agreement with the actual number of fatalities (167) observed and indicates that this model presents a good starting point for building failure following a hazard. Clearly, the above model is empirical and the proposed values for the modifiers will require refinement and validation based on further case studies. More detailed

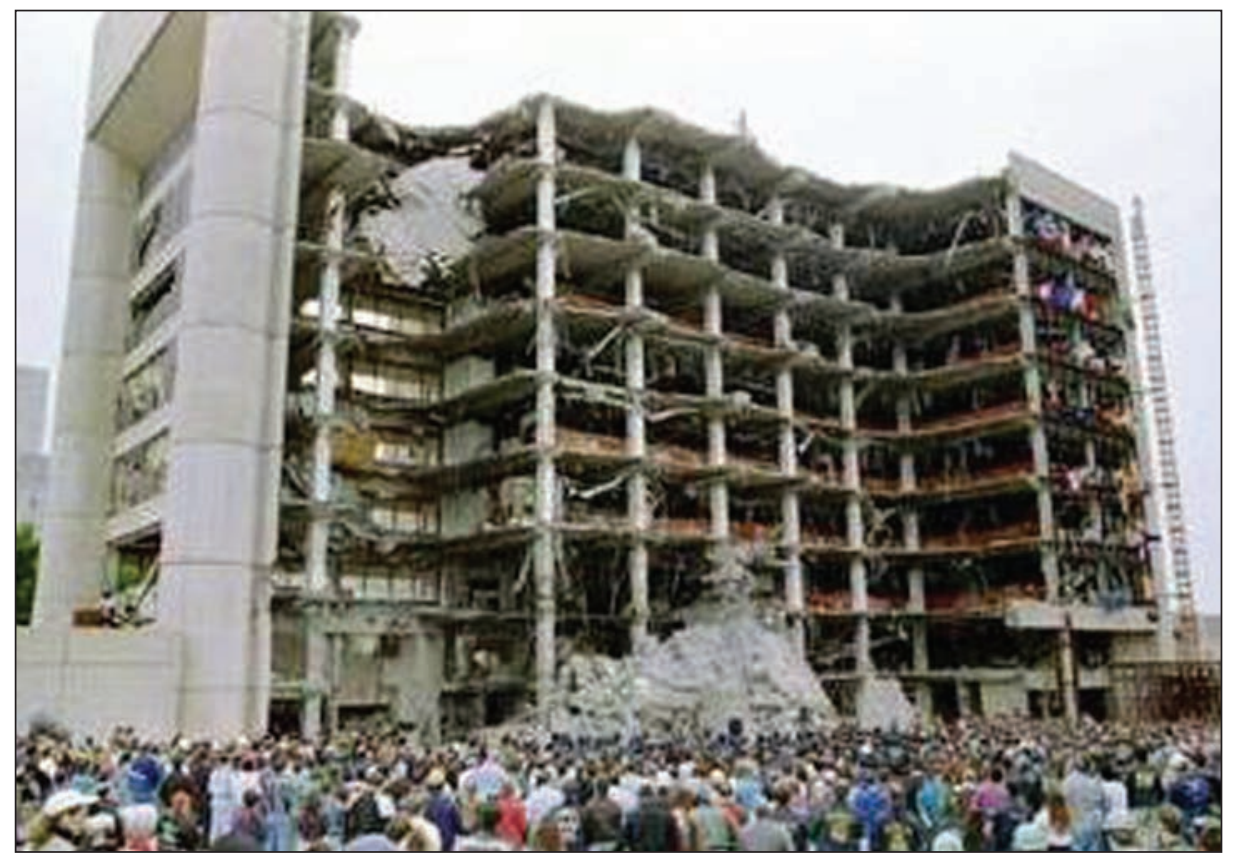

Fig. 2: Murrah Building bombing

models could be developed but they depend on input which is rarely available a priori.

Once the estimated number of ratalities has been determined, one may wish to convert this in o monetary terms so that an overall "tailure cost" may be computed. In Inplementing such an approacl, the contentious issue of deterning the economic value of human-life has to be considered. A race range of approaches can be found to estimate this value, incl ding (a) willingness-to-pay and wiling ress-to-accept approaches, (b) estimates of the value of a statistical life (VSL), (c) insured value statistics, (d) lost earnings estimates and (e) approximations of the societal value of life. More information on the specific methods available can be found in the study of Janssens et al. ${ }^{9}$ As might be expected, there is considerable variation in the cited values: reflecting varying social and economic contexts, as well as differences in scope and context. However, it may be worth noting that, in general, many estimates for the VSL lie within the $€ 1$ to $€ 2$ million range. Though, a recent paper ${ }^{10}$ suggests that in relation to life-safety risks due to terrorist threats a higher value of $\$ 7,5 \mathrm{~m}$ is typically adopted in the United States. Alternatively, the number of fatalities can be considered separately to the overall failure cost, resulting in a multi-objective optimisation problem to achieve the optimum balance between robustness and risk/ consequences.

\section{Injuries}

The development of models to predict the number of injured persons, which may be anticipated as a result of building collapse, is a more complex task. It is generally recognised that the statistics for casualty numbers from past failure events are often inconsistent. ${ }^{11,12}$ Among other factors, this can be attributed to the fact that there is no standard threshold at which victims may be classified as injured. Also, as casualty statistics are often based on the individuals seeking emergency treatment, those who seek private treatment or choose to self-medicate may not be included. Therefore, it may be more challenging to develop an injury model similar to that presented for fatalities and further work is required in relation to this.

Again, one may wish to convert the number of people injured into monetary terms. For injuries, it is likely that the "cost" may be significantly higher than that for fatalities, and could include, some or all of, pre-hospital emergency treatment, emergency department services, hospital services, visits to private physicians, rehabilitation costs, lost income and insurance compensation received. A large amount of research has been undertaken in the medical profession on this topic. The World Health Organisation (WHO) ${ }^{13}$ provides a detailed review of the factors contributing to injuries and of the techniques (e.g. "cost-of-illness") used to evaluate the cost of related consequences. Additionally, the WHO 


\begin{tabular}{|l|l|c|}
\hline $\begin{array}{l}\text { Injury } \\
\text { scale }\end{array}$ & Category & $\begin{array}{l}\text { Percentage of } \\
\text { fatality cost }\end{array}$ \\
\hline 0 & No injury & - \\
\hline 1 & Minor & 0,5 \\
\hline 2 & Moderate & 5 \\
\hline 3 & Serious & 10 \\
\hline 4 & Severe & 20 \\
\hline 5 & $\begin{array}{l}\text { Critical (survival } \\
\text { uncertain) }\end{array}$ & 70 \\
\hline 6 & Fatal & 100 \\
\hline
\end{tabular}

Table 3: Proposed injury classification and associated costs

CHOICE project has produced costs per hospital stay by hospital level, outpatient visits and cost of outpatient visits, for the $14 \mathrm{WHO}$ regions. On the other hand, an approach similar to that used in the transport sector could be adopted, where the injury cost is expressed as a percentage of the fatality cost adopted. ${ }^{14}$ Table 3 presents a possible injury classification and its relationship to fatality costs, based on the approaches outlined in Reference $[15,16]$. The values in Table 3 do not take into account long-term effects associated with injury recuperation and recovery that could lead to the overall injury cost being greater than $100 \%$ of the assumed fatality cost. Finally, given such uncertainties and complexities, the number of injuries could also be considered separately using the vector representation recommended earlier.

\section{Replacement/Repair of Structure}

Following partial/total collapse of a building the most substantial economic consequence is likely to be the cost of repair or replacement of the building and its contents. This is also likely to be the simplest (relatively) to estimate and can be divided into two categories: the cost of replacement or repair of the structural components (structural cost) and the cost of replacement or repair of its contents (non-structural cost).

The structural cost will be dependent on the extent of damage, structure type, size, etc. and can be estimated from the initial construction cost. This value should account for all building components, including piping, mechanical and electrical systems, building materials and built-in fixtures. The building replacement cost models used in Hazus ${ }^{12}$ are based on industry-standard cost-estimation models and provide a good starting point for estimating this term.

Meanwhile, the non-structural cost will depend on the market price and nature of the contents, which should both be taken into account, as well as the extent of damage. This can be more difficult to quantify, requiring greater detail about the function of the structure. Hazus simplifies the estimation of non-structural costs by assuming the non-structural cost is directly related to the structural cost. This is also considered to be a reasonable assumption for consequence analysis as part of a robustness assessment.

Table 4 lists the cost for full replacement of the structure for a selection of structures with high potential consequences of failure (defined as buildings with more than 15 storeys or greater than $5000 \mathrm{~m}^{2}$, i.e. CC3 buildings according to EN 1991- ${ }^{2}$ ). These estimates are based on the US construction market; however, they could be adapted for different nations as necessary. Additionally, the approximate ratios of the structural cost to the non-structural costs proposed in Hazus are also given.

The costs given in Table 4 represent those associated with total collapse of the structure. For partial collaps as a result of a hazard, an app oacin similar to that used in earthquake engineering loss estimation stumes would be appropriate: where tire cost of repair or replacement related to a damage severity index (possibly related to the percertoo floor area or volume damaged $\left.{ }^{9}\right)$.

\section{Otho Economic Consequences}

Additionally, economic consequences such as loss of functionality and

\begin{tabular}{|c|c|c|}
\hline Building description & $\begin{array}{l}\text { Structural cost USD/ft' } \\
\left(\mathbf{U S D} / \mathbf{m}^{2}\right)\end{array}$ & $\begin{array}{l}\text { Structural cost : } \\
\text { non-structural cost }\end{array}$ \\
\hline $\begin{array}{l}\text { Apartment block } \\
8 \text { to } 24 \text { storeys; } 145000 \mathrm{ft}^{2}\left(13500 \mathrm{~m}^{2}\right)\end{array}$ & $111,69(10,38)$ & \multirow[t]{3}{*}{$1: 0,5$} \\
\hline $\begin{array}{l}\text { Hotel } \\
8 \text { to } 24 \text { storeys; } 450000 \mathrm{ft}^{2}\left(41800 \mathrm{~m}^{2}\right)\end{array}$ & $93,47(8,68)$ & \\
\hline $\begin{array}{l}\text { Underground parking lot } \\
100000 \mathrm{ft}^{2}\left(9300 \mathrm{~m}^{2}\right)\end{array}$ & $49,2(4,57)$ & \\
\hline $\begin{array}{l}\text { Department store } \\
1 \text { storey; } 110000 \mathrm{ft}^{2}\left(10200 \mathrm{~m}^{2}\right)\end{array}$ & $71,54(6,65)$ & \multirow[t]{4}{*}{$1: 1$} \\
\hline $\begin{array}{l}\text { Large warehouse } \\
1 \text { storey; } 60000 \mathrm{ft}^{2}\left(5600 \mathrm{~m}^{2}\right)\end{array}$ & $56,58(5,26)$ & \\
\hline $\begin{array}{l}\text { Offices } \\
11 \text { to } 20 \text { storeys; } 260000 \mathrm{ft}^{2}\left(24200 \mathrm{~m}^{2}\right)\end{array}$ & $88,21(8,19)$ & \\
\hline $\begin{array}{l}\text { School } \\
130000 \mathrm{ft}^{2}\left(12000 \mathrm{~m}^{2}\right)\end{array}$ & $92,8(8,62)$ & \\
\hline $\begin{array}{l}\text { Hospital } \\
4 \text { to } 8 \text { storeys; } 200000 \mathrm{ft}^{2}\left(18600 \mathrm{~m}^{2}\right)\end{array}$ & $125,6(11,67)$ & $1: 1,5$ \\
\hline
\end{tabular}

Table 4: Structural and non-structural costs (based on Hazus ${ }^{12}$ ) for buildings with high consequences of failure (i.e. CC3 buildings in EN 1991-1-72) regional economic effects can be included in the analysis. For a business, a measure of loss of functionality can be computed from predictions of the lost gross domestic product or lost value added. Whereas, for residential buildings (as well as some offices and retail units), any loss of functionality will probably incur costs related to the the occupants. This can be estimated using appropriate rental values for the area.

Lastly, the economic consequences can also include intangible factors such as the effect of a building failure on the regional economy and any loss of reputation experienced. Although these consequences are more difficult to evaluate, they can be considerable. For example, the impact of the collapse of the World Trade Centre Twin Towers on the regional economy has been estimated to be between 7,2 and 64,3 billion USD. ${ }^{17}$ Therefore, for landmark buildings, a consequence analysis should go some way towards including these effects. In such cases, special attention is warranted with regard to the definition of the appropriate spatial and temporal domain, since indirect losses can readily dwarf direct losses due to damage and even collapse of the specific building experiencing the hazard.

\section{$\mathrm{CO}_{2}$ Emissions}

In most cases, the environmental consequences are represented by the estimated level of $\mathrm{CO}_{2}$ emitted, during clean-up and reconstruction of the temporary relocation requirement of 


\begin{tabular}{|l|l|}
\hline Material & $\mathbf{C O}_{2}$ emitted \\
\hline Steel & $1820 \mathrm{~kg} \mathrm{CO}_{2} / \mathrm{t}$ \\
\hline Cement & $800 \mathrm{~kg} \mathrm{CO}_{2} / \mathrm{t}$ \\
\hline $\begin{array}{l}\text { Reinforced } \\
\text { concrete }\end{array}$ & $260-450 \mathrm{~kg} \mathrm{CO}_{2} / \mathrm{t}$ \\
\hline
\end{tabular}

Table 5: $\mathrm{CO}_{2}$ content per tonne for some typical building materials

damaged building. The $\mathrm{CO}_{2}$ emissions may be computed by multiplying estimates of the quantity of different building materials required by values similar to those shown in Table 5. Furthermore, the $\mathrm{CO}_{2}$ emissions for any associated transport may also be included in this term. Additionally, the release of pollutants and the cost of environmental studies and any related repair may be included, however, these are likely to be considerable only for special structures (e.g. nuclear power plants), which are outside the scope of this paper.

These quantities can be converted to monetary units, though, at present there is a wide range of values quoted for the economic cost of $\mathrm{CO}_{2}$ emissions. ${ }^{14}$ Until a greater degree of consensus is achieved, it might be sensible to consider environmental costs as a separate component of the consequence vector, with its significance assessed through appropriate stakeholder engagement and contextual input.

\section{Conclusions}

This paper has outlined the steps which may be followed when performing a consequence analysis, as part of a risk based robustness evaluation. The range of consequences which may arise as a result of building failure (following a hazard) have been discussed, and the complexity and variability in their estimates were highlighted. Additionally, a categorisation of failure consequences and associated models for their quantification has been presented.

Clearly, developing and validating models for estimating the consequences arising as a result of building failure is not an easy task. This is due to a number of reasons, including the fact that the events under consideration are relatively rare. Also, detailed information regarding the consequences of such events is scarce. Further detailed investigations of the consequences of past events should be undertaken, to refine the models proposed in this paper and to allow the development of a probabilistic approach capturing the full range of uncertainties associated with the various consequence types. A multidisciplinary approach may be useful in undertaking such studies, as it is likely that similar work is being undertaken in, for example, medicine, economics and sociology. However, the input from civil engineers is key, as they have to be familiar both with the models used and the context in which these are applied for particular structures.

\section{Acknowledgements}

This work was developed in the course of COST Action TU0601: Robustness of Structures. The authors would like to thank the participants of the action, particularly those in Working Group 3, for many fluitful discussions. The financial suppent piovided by the COST office is also 8 a tefully acknowledged.

\section{References}

[1] European Comrintec for Standardisation (CEN). Eurocode 0 . Dasis of Structural Design. BS EN 1990:2002: brussels, 2002.

[2] European Committee for Standardisation (CEN). Eu. ocode 1: Actions on Structures - Part 1-7. Gu ne al actions; Accidental actions. BS EN 1901-1 7:2006: Brussels, 2006.

[3] Baker JW, Schubert M, Faber MH. On the assessment of Robustness. Struct. Safe. 2008; 30(3): 253-267.

[4] Joint Committee on Structural Safety (JCSS). Risk assessment in engineering. 2008. www.jcss. ethz.ch

[5] Coburn A, Spence R, Pomonis A. Factors Determining Human Casualty Levels in Earthquakes: Mortality Prediction in Building Collapse. 10th World Conference on Earthquake Engineering (10WCEE). A. A. Balkema: Madrid, 1992.

[6] Federal Emergency Management Agency (FEMA). The Oklahoma City Bombing: Improving Building Performance through Multihazard Mitigation. FEMA: Washington, DC, 1996. Document no. FEMA 277. www.fema.gov
[7] Mallonee S, Shariat S, Stennies G, Waxweiller R, Hogan D, Jordan F. Physical injuries and fatalities resulting from the Oklahoma City Bombing. J. Am. Med. Assoc. 1996; 276(5): 382-387.

[8] Coburn A, Spence R. Earthquake Protection, 2nd edn. John Wiley \& Sons: Chichester, 2002.

[9] Janssens V, O'Dwyer DW, Chryssanthopoulos MK. Building Failure Consequences. Robustness of structures: Proceedings of the final conference of COST Action TU0601, Prague, Czech Republic. Czech Technical University in Prague, 2011.

[10] Stewart MG. Life-safety risks and optimisation of protective measures against terrorist threats to infrastructure. Struct. Infrastruct. Eng. 2011; 7(6): 431-440.

[11] Spence R. Earthquake Disaster Scenario Prediction and Loss Modelling for Urban Areas. LESSLOSS Report No 2007/07: Pavia, 2007.

[12] Federal Emergency Management Agency (FEMA). Hazus-MH MR3 Technical Manual. FEMA: Washington, DC, 2003. www.fema.gov

[13] World Health Organisation (WHO). Guide to Identifying the Economic Consequences of Disease and Injury. WHO: Geneva, 2009. www. who.int

[14] Imam BM, Chryssanthopoulos MK. Consequences of Failure: Bridges. Robustness of structures: Proceedings of the final conference of COST Action TU0601, Prague, Czech Republic. Czech Technical University in Prague, 2011.

[15] Blincoe L, Seay A, Zaloshnja E, Miller T, Romano E, Luchter S, Spicer R. The Economic Impact of Motor Vehicles Crashes 2000. US Department of Transportation, National Highway Traffic Safety Administration: Washington DC, 2002.

[16] Wong SM, Onof CJ, Hobbs RE. Models for evaluating the costs of bridge failure. Proceedings of the Institution of Civil Engineers (ICE) - Bridge Engineering. 2005; 158(BE3): 117-28.

[17] Faber MH, Kübler O, Fontana M, Knobloch M. Failure Consequences and Reliability Acceptance Criteria for Exceptional Building Structures: A Study Taking Basis in the Failure of the World Trade Center Twin Towers. Swiss Federal Institute of Technology: Zürich, 2004.

\section{Further Information}

1. COST Action TU0601 homepage: www.costtu0601.ethz.ch

2. LESSLOSS project homepage: www.lessloss. org

3. Hazus - natural hazard loss estimation methodology: www.fema.gov/plan/prevent/hazus

4. WHO CHOICE project:www.who.int/ choice 